\title{
Schmerzsyndrome
}

\section{Frauen leiden anders, häufiger und stärker}

\begin{abstract}
Schmerzerkrankungen treffen Frauen nicht nur häufiger, sondern auch härter als Männer. Zum einen liegt ihre Schmerzschwelle niedriger, zum anderen tolerieren sie Schmerzen schlechter. Dafür verfügen sie über eine breitere Palette von Strategien, mit denen sie Schmerzen bekämpfen.
\end{abstract}

- Bei der Schmerzforschung bewahrheiten sich offenbar alle Klischees über Geschlechtsunterschiede, die der Volksmund parat hält: Dass Frauen empfindlicher sind und dass Männer „mehr aushalten“. Bildgebungsstudien zeigen tatsächlich Unterschiede in der zentralen Verarbeitung von Schmerzreizen, berichtete Prof. Dr. Karen Berkley, Universität Tallahassee.
Bei den meisten Schmerzsyndromen gibt es eine ausgeprägte weibliche Dominanz, so bei der Trigeminusneuralgie, dem Karpaltunnelsyndrom und der Fibromyalgie. Männer leiden häufiger an Kopfschmerzen, Gicht oder Zosterneuralgien. Die Erfahrung, dass sich Schmerzen bei Männern und Frauen unterschiedlich äußern, wird durch die Forschung bestätigt. Bei der KHK etwa klagen Frauen öfter über ungewöhnliche Schmerzausstrahlung in Hals, Kiefer und Rücken. Das Reizdarmsyndrom, insgesamt eine weibliche Domäne, verursacht bei beiden Geschlechtern insgesamt gleich starke Beschwerden. Bestimmte Symptome wie Blähungen und Obstipation kommen bei Frauen aber öfter vor.
Bei der Schmerztherapie reagieren Frauen auf Opioide weniger ausgeprägt, möglicherweise weil sie oft weitere rezeptfreie Analgetika nehmen und alternative Maßnahmen inklusive Phytotherapeutika anwenden.

Auch bei den Nebenwirkungen scheint es Unterschiede zu geben. So treten allergische Reaktionen auf neuromuskuläre Hemmstoffe bei Frauen öfter auf, während Männer stärker zu kardialen Komplikationen neigen. Welche Konsequenzen aus all diesen Unterschieden zu ziehen sind, bleibt zu erforschen. Berkley warnte davor, die Schmerztherapie zu stark zu "genderisieren“: Im Zentrum müsse immer das Individuum stehen, egal welchen Geschlechts es ist.

ARA =

\section{Mehr Aborte, mehr Frühgeburten}

\section{Jungen sind schon im Mutterleib benachteiligt}

\author{
Für Gesundheit und Überlebens- \\ chancen ist es gar nicht gut, ein \\ Mann zu sein. Das beginnt bereits \\ im Mutterleib. Der negative Einfluss \\ des Y-Chromosoms macht sich sogar \\ bei Zwillingsschwangerschaften \\ bemerkbar, wie israelische Forscher \\ feststellen mussten.
}

- Bei der Befruchtung entstehen auf 100 weibliche 170 männliche Embryos, aber geboren werden etwas mehr Mädchen als Jungen. Das liegt vor allem daran, dass Aborte bei männlichen Feten dreimal so häufig sind, berichtete Prof. Marek Glezerman, Rabin Medical Center, Tel Aviv. Auch sonst läuft es schlechter, wenn das Kind ein Junge wird, ergab die retrospektive Analyse von über 66000 Schwangerschaften: Es gab doppelt so viele Makrosomien, 70\% mehr Frühgeburten, 50\% mehr vorzeitige Blasensprünge und Zangen- geburten. Nur bei Wachstum und Gewicht lagen die Mädchen hinten.

Ein bemerkenswertes Ergebnis förderte die Analyse von 2700 Zwillingsschwangerschaften zutage. Den besten Verlauf im Hinblick auf Frühgeburten, Geburtsgewicht, Geburtskomplikationen und respiratorische oder neurologische Probleme nach der Geburt nah-

\section{$\nabla$ Bessere Chancen, wenn es ein Mädchen ist?}

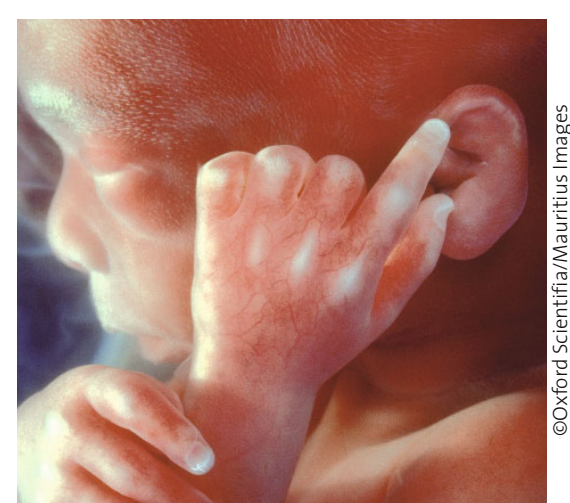

men Schwangerschaften mit zwei Mädchen, den schlechtesten jene mit zwei Knaben. Mädchen, die den Uterus mit einem Jungen teilen mussten, wiesen ähnlich schlechte Ergebnisse auf wie Knaben aus einer rein männlichen Zwillingsschwangerschaft.

Prof. Glezermans Fazit: „Wenn Sie ein Zwilling sind, egal welchen Geschlechts, sollten Sie hoffen, dass Ihr intrauteriner Gegenpart weiblich ist.“

Die Weichen für die Geschlechtsentwicklung werden übrigens etwa in der achten Schwangerschaftswoche gestellt. Dann wird ein Gen auf dem kurzen Arm des Y-Chromosoms für wenige Stunden angeschaltet, das einige andere Gene aktiviert, die ihrerseits die Hodenentstehung steuern.

Manuela ARAND

- Quelle: 4. Kongress der International Society of Gender Medicine, Berlin, 6. bis 8. 11. 2009 